\title{
Saccharopolyspora rosea sp. nov., isolated from a patient with bronchial carcinoma
}

\author{
Correspondence \\ A. F. Yassin \\ yassin@mibi03.meb.uni-bonn.de
}

\author{
A. F. Yassin \\ Institut für Medizinische Mikrobiologie und Immunologie der Universität Bonn, 53127 Bonn, \\ Germany
}

\begin{abstract}
The taxonomic status of a bacterium isolated from a patient with bronchial carcinoma was established using a polyphasic taxonomic approach. The strain had morphological and chemotaxonomic characteristics consistent with those of members of the genus

Saccharopolyspora. The generic assignment was confirmed by comparative analysis of the $16 \mathrm{~S}$ rRNA gene sequence, which showed that the strain constituted a distinct phyletic line, displaying 93.5-96.9\% sequence similarity with respect to members of the genus Saccharopolyspora. The isolate was distinguished from the type strains of recognized members of the genus Saccharopolyspora by means of various biochemical tests. The genotypic and phenotypic data obtained demonstrated that strain IMMIB L-1070 ${ }^{\top}$ represents a novel species of the genus Saccharopolyspora, for which the name Saccharopolyspora rosea sp. nov. is proposed. The type strain is IMMIB L-1070 $\left(=\right.$ DSM $45226^{\top}=$ CCUG $\left.56401^{\top}\right)$.
\end{abstract}

The genus Saccharopolyspora was first described by Lacey \& Goodfellow (1975) and (at the time of writing) contains 13 species with validly published names: Saccharopolyspora antimicrobica (Yuan et al., 2008); S. cebuensis (PimentelElardo et al., 2008), S. erythraea (Labeda, 1987), S. flava (Lu et al., 2001), S. gregorii (Goodfellow et al., 1989), S. hirsuta (Lacey \& Goodfellow, 1975), S. hordei (Goodfellow et al., 1989), S. rectivirgula (Korn-Wendisch et al., 1989), S. shandongensis (Zhang et al., 2008), S. spinosa (Mertz \& Yao, 1990), S. spinosporotrichia (Zhou et al., 1998), S. taberi (Labeda, 1987; Korn-Wendisch et al., 1989) and S. thermophila (Lu et al., 2001). Representatives of these species form a distinct phyletic line within the evolutionary radiation encompassed by the family Pseudonocardiaceae and can be distinguished using a combination of biochemical, morphological and physiological properties (Embley, 1992). During the course of the identification of bacterial isolates encountered in clinical specimens, a hitherto unknown filamentous, thermotolerant bacterium was characterized that did not correspond to any recognized taxon. On the basis of the results of a polyphasic taxonomic study, a novel species of the genus Saccharopolyspora is described.

Strain IMMIB L- $1070^{\mathrm{T}}$ was isolated from a bronchial lavage sample from a 45-year-old patient with bronchial carcinoma. After treatment of the bronchial lavage sample with $\mathrm{N}$-acetylcysteine, the strain was isolated on Löwenstein-Jensen medium and subsequently cultured on Columbia agar supplemented with $5 \%$ sheep blood

The GenBank/EMBL/DDBJ accession number for the 16S rRNA gene sequence of strain IMMIB L-1070 is AM992060. agar and brain heart infusion agar. The organism was grown on yeast extract-malt extract agar (ISP2 medium), oatmeal agar (ISP3 medium) and inorganic salts-starch agar (ISP4 medium) as described by Shirling \& Gottlieb (1966) and was examined for pigmentation, for production of aerial mycelium and for other morphological characteristics. Air-dried smears from Columbia agar were stained using the standard Gram and Ziehl-Neelsen methods in order to determine the Gram stain and acid-fastness, respectively. The micromorphology of the organism was determined by using a culture grown at $37{ }^{\circ} \mathrm{C}$ on ISP2 medium. Growth temperatures were determined on Columbia agar by incubating the organism at $28,37,42$ and $50{ }^{\circ} \mathrm{C}$. The physiological properties of strain IMMIB $\mathrm{L}-1070^{\mathrm{T}}$ were determined by using tests to investigate hydrolysis of complex substrates, as described previously (Gordon, 1966, 1967; Gordon \& Mihm, 1957), as well as tests to determine carbon-source utilization (as described by Yassin et al., 1995). Melanoid pigment production was determined using peptone-yeast extract-iron agar (ISP6 medium) and tyrosine agar (ISP7 medium) as described by Shirling \& Gottlieb (1966). The isomeric form of the diaminopimelic acid was determined using the methods of Becker et al. (1964) and the whole-cell sugars were determined using the method of Lechevalier (1968). Lipids were extracted using acid methanolysis and mycolic acids were detected by means of TLC as described by Minnikin et al. (1980). Non-hydroxylated fatty acids were analysed as described recently by Yassin et al. (2007). Polar lipids were extracted, purified and identified using twodimensional TLC as described by Yassin et al. (1993). Menaquinones were extracted and purified as described by 
Collins et al. (1977). Mass spectral analyses of the menaquinones were recorded as described by Yassin \& Hupfer (2006) in positive-ion mode on a Q-TOF 2 mass spectrometer (Micromass) equipped with a nanospray source.

Genomic DNA extraction, PCR-mediated amplification of the 16S rRNA gene sequence and purification of PCR products were carried out using procedures described previously (Rainey et al., 1996). The purified PCR products were sequenced using a Taq DyeDeoxy terminator cycle sequencing kit (Applied Biosystems) as described in the manufacturer's protocol. A Genetic Analyzer (model 310; Applied Biosystems) was used for electrophoresis of the sequencing reaction products. The $16 \mathrm{~S}$ rRNA gene sequences of isolate IMMIB L-1070 ${ }^{\mathrm{T}}$ and recognized members of the genus Saccharopolyspora (obtained from GenBank) were added to the ARB database (Ludwig et al., 2004) and aligned using the respective tool from the ARB package. The resulting alignment was corrected manually and evolutionary trees were inferred using maximumparsimony (Fitch, 1971), neighbour-joining (Saitou \& Nei,
1987) and maximum-likelihood (Felsenstein, 1981) methods. The evolutionary distance matrix for the neighbourjoining method was calculated using the correction of Jukes \& Cantor (1969). The topology of the neighbour-joining tree was evaluated using bootstrap analyses (Felsenstein, 1985) based on 500 resamplings.

Cultures of strain IMMIB L-1070 ${ }^{\mathrm{T}}$ produced abundant growth on Columbia agar and ISP2, ISP3 and ISP4 media. On these ISP media, the organism formed yellowish to brownish yellow, extensively branched substrate mycelia that fragmented into rod-shaped elements. The aerial hyphae were yellowish to white and differentiated into long chains of smooth-surfaced spores. A pink-coloured diffusible pigment was weakly produced on ISP2 and ISP3 media, whereas strong production of this pigment was observed on ISP4 medium. The organism was found to be aerobic, and the hyphae stained Gram-positive and were non-acid-alcohol fast. A battery of phenotypic and biochemical tests were performed on strain IMMIB $\mathrm{L}-1070^{\mathrm{T}}$, the results of which are given in the species description and Table 1.

Table 1. Differential physiological properties of strain IMMIB L-1070 and the type strains of the species of the genus Saccharopolyspora

Strains: 1, IMMIB L-1070 $; 2$, S. cebuensis SPE 10-1 ${ }^{\mathrm{T}} ; 3$, S. gregorii DSM $44324^{\mathrm{T}} ; 4$, S. spinosporotrichia DSM 44350 ${ }^{\mathrm{T}} ; 5$, S. spinosa DSM 44228 ${ }^{\mathrm{T}}$; 6 , S. erythraea DSM $40517^{\mathrm{T}}$; 7, S. hirsuta subsp. hirsuta DSM $43463^{\mathrm{T}}$; 8, S. hordei DSM 44065 ${ }^{\mathrm{T}}$; 9, S. rectivirgula DSM 43747 ${ }^{\mathrm{T}}$; 10, S. flava AS4.1520 ${ }^{\mathrm{T}}$; 11 , S. thermophila AS4.1511 $1^{\mathrm{T}}$; 12 , S. taberi DSM $43856^{\mathrm{T}} ; 13$, S. shandongensis JCM $14614^{\mathrm{T}}$; 14 , S. antimicrobica I05-00074 ${ }^{\mathrm{T}}$. Data for strain IMMIB L$1070^{\mathrm{T}}$ are from this study; data for all other strains are from Pimentel-Elardo et al. (2008) and Lu et al. (2001), except for data concerning utilization of hypoxanthine and D-mannitol, which are from Goodfellow et al. (1989), Labeda (1987), Lacey \& Goodfellow (1975), Mertz \& Yao (1990) and Zhou et al. (1998). S. cebuensis SPE 10-1 ${ }^{\mathrm{T}}$ is the only known species of the genus Saccharopolyspora with a strict requirement for salt. + , Positive; -, negative; ND, not determined.

\begin{tabular}{|c|c|c|c|c|c|c|c|c|c|c|c|c|c|c|}
\hline Characteristic & 1 & 2 & 3 & 4 & 5 & 6 & 7 & 8 & 9 & 10 & 11 & 12 & 13 & 14 \\
\hline \multicolumn{15}{|l|}{ Utilization of: } \\
\hline L-Arabinose & + & + & + & - & + & + & - & + & - & - & - & - & + & + \\
\hline D-Lactose & - & + & - & - & - & - & + & + & + & + & + & + & - & + \\
\hline Maltose & + & + & + & + & - & + & + & + & + & + & + & + & + & + \\
\hline D-Mannitol & + & - & + & + & + & + & + & + & + & + & + & + & $\mathrm{ND}$ & ND \\
\hline L-Rhamnose & - & + & + & + & - & + & + & + & + & + & + & + & + & + \\
\hline Sucrose & + & + & + & + & - & + & + & + & + & + & + & + & + & + \\
\hline D-Xylose & + & + & + & + & - & + & + & + & + & + & - & + & + & + \\
\hline $\begin{array}{l}\text { Temp. range for } \\
\text { growth }\left({ }^{\circ} \mathrm{C}\right)\end{array}$ & $22-42$ & $15-37$ & $10-35$ & $28-37$ & $15-37$ & $20-42$ & $25-50^{*}$ & $20-60$ & $37-63^{\star}$ & $28-37$ & $45-55$ & $20-45$ & $15-38$ & $20-45$ \\
\hline Nitrate reduction & - & - & - & - & + & + & - & - & + & + & - & + & + & + \\
\hline Elastin & - & $\mathrm{ND}$ & + & + & - & + & + & + & - & - & - & + & + & - \\
\hline Hypoxanthine & + & - & + & + & + & + & + & + & + & + & - & + & + & + \\
\hline Tyrosine & + & + & + & - & + & + & + & + & + & - & + & + & + & + \\
\hline
\end{tabular}

${ }^{\star}$ The temperature data from Lu et al. (2001) for the type strains differ slightly from those of Korn-Wendisch et al. (1989), who reported temperature ranges of $20-50{ }^{\circ} \mathrm{C}$ for S. hirsuta and $37-60{ }^{\circ} \mathrm{C}$ for S. rectivirgula. 
Cell-wall analysis revealed that strain IMMIB L-1070 ${ }^{\mathrm{T}}$ contained chemical markers that supported its assignment to the genus Saccharopolyspora. The cell wall contained meso-diaminopimelic acid as well as arabinose and galactose (i.e. wall chemotype IV sensu Lechevalier \& Lechevalier, 1970). Analysis of the non-hydroxylated cellular fatty acids of strain IMMIB L-1070 ${ }^{\mathrm{T}}$ revealed the presence of straight-chain, saturated fatty acids $\mathrm{C}_{14: 0}$ (0.3\% of total fatty acids), $\mathrm{C}_{15: 0}(0.8 \%), \mathrm{C}_{16: 0}(2.1 \%)$, $\mathrm{C}_{17: 0}(8.4 \%)$ and $\mathrm{C}_{18: 0}(0.3 \%)$ and branched-chain fatty acids iso- $\mathrm{C}_{15: 0}(8.6 \%)$, anteiso- $\mathrm{C}_{15: 0}(3.5 \%)$, iso- $\mathrm{C}_{16: 0}$ $(12.8 \%)$, iso- $\mathrm{C}_{17: 0}(15.5 \%)$, anteiso- $\mathrm{C}_{17: 0}(42.2 \%)$ and iso- $\mathrm{C}_{18: 0}(0.9 \%)$. Polar lipid analysis showed that the organism contained diphosphatidylglycerol, phosphatidylglycerol, phosphatidylcholine and phosphatidylinositol as the characteristic phospholipids (i.e. phospholipid type PIII sensu Lechevalier et al., 1977). Mass spectral analysis of the respiratory quinones showed that a tetrahydrogenated menaquinone with nine isoprene units, MK-9 $\left(\mathrm{H}_{4}\right)$, was the predominant menaquinone. In addition, a substantial amount of a tetrahydrogenated menaquinone with 10 isoprene units, MK-10 $\left(\mathrm{H}_{4}\right)$, was detected.

To ascertain the phylogenetic relationships of strain IMMIB L-1070 ${ }^{\mathrm{T}}$, the almost-complete $16 \mathrm{~S}$ rRNA gene sequence of the novel strain (1492 nt) was determined in this study. Comparative $16 \mathrm{~S}$ rRNA gene sequence analysis revealed that strain IMMIB L- $1070^{\mathrm{T}}$ displayed highest sequence similarities with respect to species of the family Pseudonocardiaceae (data not shown). Strain IMMIB L- $1070^{\mathrm{T}}$ displayed highest sequence similarity (93.5$96.9 \%$ ) with species of the genus Saccharopolyspora. Phylogenetic analysis confirmed the association of strain
IMMIB L-1070 ${ }^{\mathrm{T}}$ with the genus Saccharopolyspora, with the strain forming a distinct subline. A phylogenetic tree for strain IMMIB L- $1070^{\mathrm{T}}$, constructed with the neighbourjoining method, is shown in Fig. 1. It is evident from the tree that strain IMMIB L-1070 ${ }^{\mathrm{T}}$ displays a phylogenetic affinity with a subcluster of species consisting of $S$. gregorii and S. cebuensis; however, the branching of the strain at the base of this subcluster was not supported by either bootstrap analysis or other treeing methods. Strain IMMIB L-1070 ${ }^{\mathrm{T}}$ showed highest sequence similarities with respect to S. spinosa DSM $44228^{\mathrm{T}}(96.9 \%)$, S. shandongensis $88^{\mathrm{T}}(96.7 \%)$, S. gregorii ATCC $51265^{\mathrm{T}}(96.3 \%)$, S. antimicrobica $\mathrm{I} 05-00074^{\mathrm{T}}(96.2 \%)$ and S. cebuensis DSM $45019^{\mathrm{T}}(96.1 \%)$; other species showed lower levels of sequence similarity. However, it is generally accepted that organisms displaying $\geqslant 3 \% 16 \mathrm{~S}$ rRNA gene sequence divergence are not members of the same species (Stackebrandt \& Goebel, 1994). Support for the distinctiveness of strain IMMIB L- $1070^{\mathrm{T}}$ is also evident from phenotypic data: the strain can be readily distinguished from all of the recognized members of the genus Saccharopolyspora (Table 1). In particular, it differed from S. spinosa DSM $44228^{\mathrm{T}}$ by its ability to utilize D-galactose, maltose, sucrose and D-xylose as carbon sources and by its ability to hydrolyse adenine and casein. Strain IMMIB $\mathrm{L}-1070^{\mathrm{T}}$ can also be distinguished biochemically from $S$. shandongensis $88^{\mathrm{T}}$ by the inability to utilize raffinose and Lrhamnose as carbon sources and the inability to hydrolyse elastin. Similarly, strain IMMIB L- $1070^{\mathrm{T}}$ varies from $S$. gregorii ATCC $51265^{\mathrm{T}}$ by its ability to hydrolyse adenine and the inability to utilize raffinose and L-rhamnose as carbon sources. Therefore, on the basis of both phenotypic and phylogenetic criteria, strain IMMIB L- $1070^{\mathrm{T}}$ represents

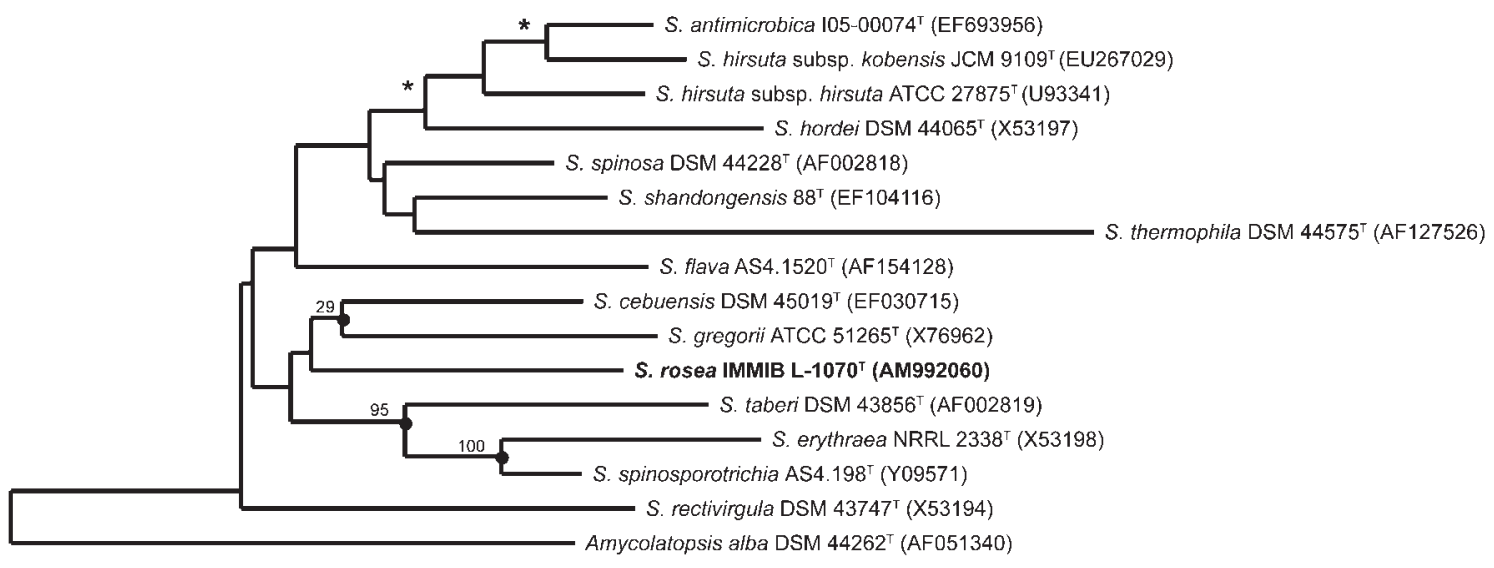

5.0

Fig. 1. Neighbour-joining phylogenetic tree, based on 16S rRNA gene sequences, showing the position of strain IMMIB $\mathrm{L}-1070^{\top}$ within the radiation of species of the genus Saccharopolyspora. Numbers at nodes indicate bootstrap percentages (based on 500 resampled datasets). Filled circles indicate that the corresponding nodes (groupings) were also recovered in maximum-likelihood and maximum-parsimony trees. Asterisks indicate that the corresponding nodes were recovered only in the neighbour-joining and maximum-likelihood trees. Bar, 5.0\% sequence divergence. 
a novel species of the genus Saccharopolyspora, for which the name Saccharopolyspora rosea sp. nov. is proposed.

\section{Description of Saccharopolyspora rosea sp. nov.}

Saccharopolyspora rosea (ro.se'a. L. fem. adj. rosea rosecoloured, pink, referring to the colour of the diffusible pigment produced by the organism).

Cells are aerobic, catalase-positive, oxidase-negative and thermotolerant, growing at $22-42{ }^{\circ} \mathrm{C}$ and $\mathrm{pH} 6.0-8.0$. Gram-positive and non-acid-alcohol fast. Forms yellowish to brownish yellow, extensively branched substrate mycelia (0.4-0.5 $\mu \mathrm{m}$ in diameter) that fragment into rod-shaped elements and carry yellowish to white aerial hyphae (0.5$0.7 \mu \mathrm{m})$ that differentiate into long chains of smoothsurfaced spores. Pink-coloured diffusible pigment is produced on ISP2, ISP3 and ISP4 media. Melanin pigment is not formed in ISP6 or ISP7 media. Adenine, aesculin, casein, gelatin, hypoxanthine, tyrosine and urea are hydrolysed; elastin, guanine, keratin, testosterone and xanthine are not hydrolysed. Nitrate is not reduced. Assimilates acetate, adipate, adonitol, iso-amyl alcohol, Larabinose, 2,3-butanediol, citrate, meso-erythritol, D-galactose, D-gluconate, D-glucose, myo-inositol, L-lactate, maltose, D-mannitol, sucrose, D-sorbitol, trehalose and D-xylose as carbon sources, but not cellobiose, $m$-hydroxybenzoate, p-hydroxybenzoate, D-lactose, melezitose, 1,2-propanediol, raffinose or L-rhamnose. Acetamide, L-alanine, arginine, gelatin, ornithine, L-proline and L-serine are utilized as simultaneous sources of carbon and nitrogen.

The type strain, IMMIB L- $1070^{\mathrm{T}}\left(=\mathrm{DSM} 45226^{\mathrm{T}}=\mathrm{CCUG}\right.$ $56401^{\mathrm{T}}$ ), was isolated from bronchial lavage from a $45-$ year-old patient with bronchial carcinoma.

\section{Acknowledgements}

Professor Dr Hans-Georg Trüper is thanked for his nomenclatural advice.

\section{References}

Becker, B., Lechevalier, M. P., Gordon, R. E. \& Lechevalier, H. A. (1964). Rapid differentiation between Nocardia and Streptomyces by paper chromatography of whole-cell hydrolysates. Appl Microbiol 12, 421-423.

Collins, M. D., Pirouz, T., Goodfellow, M. \& Minnikin, D. E. (1977). Distribution of menaquinones in actinomycetes and corynebacteria. J Gen Microbiol 100, 221-230.

Embley, T. M. (1992). The family Pseudonocardiaceae. In The Prokaryotes, vol. 1, pp. 996-1027. Edited by A. Balows, H. G. Trüper, M. Dworkin, W. Harder \& K. H. Schleifer. Berlin: Springer.

Felsenstein, J. (1981). Evolutionary trees from DNA sequences: a maximum likelihood approach. J Mol Evol 17, 368-376.

Felsenstein, J. (1985). Confidence limits on phylogenies: an approach using the bootstrap. Evolution 39, 783-791.

Fitch, W. M. (1971). Toward defining the course of evolution: minimum change for a specific tree topology. Syst Zool 20, 406-416.
Goodfellow, M., Lacey, J., Athalye, M., Embley, T. M. \& Bowen, T. (1989). Saccharopolyspora gregorii and Saccharopolyspora hordei: two new actinomycete species from fodder. J Gen Microbiol 135, 21252139.

Gordon, R. E. (1966). Some criteria for the recognition of Nocardia madurae (Vincent) Blanchard. J Gen Microbiol 45, 355-364.

Gordon, R. E. (1967). The taxonomy of soil bacteria. In The Ecology of Soil Bacteria, pp. 293-321. Edited by T. R. G. Gray \& B. Parkinson. Liverpool: Liverpool University Press.

Gordon, R. E. \& Mihm, J. M. (1957). A comparative study of some strains received as nocardiae. J Bacteriol 73, 15-27.

Jukes, T. H. \& Cantor, C. R. (1969). Evolution of protein molecules. In Mammalian Protein Metabolism, vol. 3, pp. 21-132. Edited by H. N. Munro. New York: Academic Press.

Korn-Wendisch, F., Kempf, A., Grund, E., Kroppenstedt, R. M. \& Kutzner, H. J. (1989). Transfer of Faenia rectivirgula Kurup and Agre 1983 to the genus Saccharopolyspora Lacey and Goodfellow 1975, elevation of Saccharopolyspora hirsuta subsp. taberi Labeda 1987 to species level, and emended description of the genus Saccharopolyspora. Int J Syst Bacteriol 39, 430-441.

Labeda, D. P. (1987). Transfer of the type strain of Streptomyces erthyraeus (Waksman 1923) Waksman and Henrici 1948 to the genus Saccharopolyspora Lacey and Goodfellow 1975 as Saccharopolyspora erythraea sp. nov., and designation of a neotype strain for Streptomyces erythraeus. Int J Syst Bacteriol 37, 19-22.

Lacey, J. \& Goodfellow, M. (1975). A novel actinomycete from sugarcane bagasse: Saccharopolyspora hirsuta gen. et sp. nov. J Gen Microbiol 88, 75-85.

Lechevalier, M. P. (1968). Identification of aerobic actinomycetes of clinical importance. J Lab Clin Med 71, 934-944.

Lechevalier, M. P. \& Lechevalier, H. A. (1970). Chemical composition as a criterion in the classification of aerobic actinomycetes. Int J Syst Bacteriol 20, 435-443.

Lechevalier, M. P., De Bièvre, C. \& Lechevalier, H. A. (1977). Chemotaxonomy of aerobic actinomycetes: phospholipid composition. Biochem Syst Ecol 5, 249-260.

Lu, Z., Liu, Z., Wang, L., Qi, W. \& Goodfellow, M. (2001). Saccharopolyspora flava sp. nov. and Saccharopolyspora thermophila sp. nov., novel actinomycetes from soil. Int J Syst Evol Microbiol 51, 319-325.

Ludwig, W., Strunk, O., Westram, R., Richter, L., Meier, H., Yadhukumar, Buchner, A., Lai, T., Steppi, S. \& other authors (2004). ARB: a software environment for sequence data. Nucleic Acids Res 32, 1363-1371.

Mertz, F. P. \& Yao, R. C. (1990). Saccharopolyspora spinosa sp. nov. isolated from soil collected in a sugar mill rum still. Int J Syst Bacteriol 40, 34-39.

Minnikin, D. E., Hutchinson, I. G., Caldicott, A. B. \& Goodfellow, M. (1980). Thin-layer chromatography of methanolysates of mycolic acid-containing bacteria. J Chromatogr 188, 221-233.

Pimentel-Elardo, S. M., Tiro, L. P., Grozdanov, L. \& Hentschel, U. (2008). Saccharopolyspora cebuensis sp. nov., a novel actinomycete isolated from a Philippine sponge (Porifera). Int J Syst Evol Microbiol 58, 628-632.

Rainey, F. A., Ward-Rainey, N., Kroppenstedt, R. M. \& Stackebrandt, E. (1996). The genus Nocardiopsis represents a phylogenetically coherent taxon and a distinct actinomycete lineage: proposal of Nocardiopsiaceae fam. nov. Int J Syst Bacteriol 46, 1088-1092.

Saitou, N. \& Nei, M. (1987). The neighbor-joining method: a new method for reconstructing phylogenetic trees. Mol Biol Evol 4, 406-425.

Shirling, E. B. \& Gottlieb, D. (1966). Methods for characterization of Streptomyces species. Int J Syst Bacteriol 16, 313-340. 
Stackebrandt, E. \& Goebel, B. M. (1994). Taxonomic note: a place for DNA-DNA reassociation and $16 \mathrm{~S}$ rRNA sequence analysis in the present species definition in bacteriology. Int J Syst Bacteriol 44, 846-849.

Yassin, A. F. \& Hupfer, H. (2006). Williamsia deligens sp. nov., isolated from human blood. Int J Syst Evol Microbiol 56, 193-197.

Yassin, A. F., Haggenei, B., Budzikiewicz, H. \& Schaal, K. P. (1993). Fatty acid and polar lipid composition of the genus Amycolatopsis: application of fast atom bombardment-mass spectrometry to structure analysis of underivatized phospholipids. Int J Syst Bacteriol 43, 414-420.

Yassin, A. F., Rainey, F. A., Brzezinka, H., Burghardt, J., Lee, H. L. \& Schaal, K. P. (1995). Tsukamurella inchonensis sp. nov. Int J Syst Bacteriol 45, 522-527.
Yassin, A. F., Chen, W.-M., Hupfer, H., Siering, C., Kroppenstedt, R. M., Arun, A. B., Lai, W.-A., Shen, F.-T., Rekha, P. D. \& Young, C. C. (2007). Lysobacter defluvii sp. nov., isolated from municipal solid waste. Int J Syst Evol Microbiol 57, 1131-1136.

Yuan, L.-J., Zhang, Y.-Q., Guan, Y., Wei, Y.-Z., Li, Q.-P., Yu, L.-Y., Li, W.-J. \& Zhang, Y.-Q. (2008). Saccharopolyspora antimicrobica sp. nov., an actinomycete from soil. Int J Syst Evol Microbiol 58, 1180-1185.

Zhang, J., Wu, D., Zhang, J., Liu, Z. \& Song, F. (2008). Saccharopolyspora shandongensis sp. nov., isolated from wheat-field soil. Int J Syst Evol Microbiol 58, 1094-1099.

Zhou, Z. H., Liu, Z. H., Qian, Y. D., Kim, S. B. \& Goodfellow, M. (1998). Saccharopolyspora spinosporotrichia sp. nov., a novel actinomycete from soil. Int J Syst Bacteriol 48, 53-58. 